CORRECTION

https://doi.org/10.1038/s41586-019-1109-3

\title{
Author Correction: Targeted therapy in patients with PIK3CA- related overgrowth syndrome
}

Quitterie Venot, Thomas Blanc, Smail Hadj Rabia, Laureline Berteloot, Sophia Ladraa, Jean-Paul Duong, Estelle Blanc, Simon C. Johnson, Clément Hoguin, Olivia Boccara, Sabine Sarnacki, Nathalie Boddaert, Stephanie Pannier, Frank Martinez, Sato Magassa, Junna Yamaguchi, Bertrand Knebelmann, Pierre Merville, Nicolas Grenier, Dominique Joly, Valérie Cormier-Daire, Caroline Michot, Christine Bole-Feysot, Arnaud Picard, Véronique Soupre, Stanislas Lyonnet, Jeremy Sadoine, Lotfi Slimani, Catherine Chaussain, Cécile Laroche-Raynaud, Laurent Guibaud, Christine Broissand, Jeanne Amiel, Christophe Legendre, Fabiola Terzi \& Guillaume Canaud

Correction to: Nature https://doi.org/10.1038/s41586-018-0217-9, published online 13 June 2018.

In the interests of transparency, the authors wish to amend the 'Competing interests' statement of this Article to read: "A patent application (WO2017140828A1) has been filed by INSERM (Institut National de la Santé et de la Recherche Médicale), Centre National De La Recherche Scientifique (CNRS), Université Paris Descartes, and Assistance Publique-Hôpitaux De Paris (AP-HP) for the use of BYL719 (alpelisib) in the treatment of PIK3CA-related overgrowth spectrum (PROS/CLOVES syndrome). G.C. is the inventor." The original Article has been corrected online. 